\title{
Study on Flood Control and Urban Ecological Construction of Naxi District
}

\author{
Juan Dai, Guangming Zeng, and Lingyun Li
}

\begin{abstract}
Under new social trend, new characteristics happen to the urban flood disaster---the conflict of flood disaster and water resources coexists and becomes intensified; the scientific ecological idea of "human-water harmony" is proposed and developed to guide the development of the cities in future and how to better realize urban ecological flood prevention and deal with the conflict of urban water demand has become the key point for urban construction. Through the analysis on the current situation of flood prevention of Naxi District and the analysis and calculation of flood hydrology, the planning design of urban ecological flood prevention of Naxi District is preliminarily finished under the guidance of ecological idea. The study results indicate that the simulation of urban ecological flood prevention will be deemed as one reference system for the urban planning and construction as well as the new idea and basis for the urban planning and construction in future; attempts have been made in paper study to form new standard and specification for urban planning and construction.
\end{abstract}

Index Terms—Flood control, urban ecological, Naxi District.

\section{INTRODUCTION}

Located in the southern part of Sichuan Basin, Naxi District, Luzhou City, Sichuan Province lies to the south of Yangtze River and on both banks of downstream of Yongning River. It connects Hejiang County eastward, Xuyong County southward, Jiang'an County westward and is adjacent to Jiangyang District, Luzhou City northward. The geographical coordinates are $105^{\circ} 09^{\prime} \sim 105^{\circ} 37^{\prime}$ of east longitude, $28^{\circ} 02^{\prime} 14^{\prime \prime} \sim 28^{\circ} 26^{\prime} 53^{\prime \prime}$ of north latitude with the width from east to west of $41 \mathrm{~km}$, length from south to north of $46 \mathrm{~km}$ and the area of the whole district of $1150.6 \mathrm{~km} 2$.

There are altogether over 130 rivers in different sizes in the district [1], with the total length of over $640 \mathrm{~km}$. Yangtze River flows through the northern part of the district with the total length there of $28 \mathrm{~km}$ and then flows to Luzhou through Dadukou Town, Xinle Town and Anfu. Yongning River is the largest branch of Yangtze River within the district. As the branch of Yangtze River in the southern bank, it is originated from Huangni Town, Xuyong County, runs through Xuyong and Naxi from south to north and finally affluxes to Yangtze River in Anfu Town, Naxi District with

Manuscript received April 16, 2013; revised June 8, 2013. This work is supported by the National Natural Science Foundation of China (No. 51209015)

Juan Dai is with College of Enviromental Science and Engineering, Hunan University, Changsha, China; and Changjiang River Scientific Research Institute, Wuhan, China (email: daijuan0906@sina.com).

Guangming Zeng is with College of Enviromental Science and Engineering, Hunan University, Changsha, China.

Lingyun $\mathrm{Li}$ is with Changjiang River Scientific Research Institute, Wuhan, China. the total length of $152 \mathrm{~km}$ and the catchment area of $2,320 \mathrm{~km} 2$.

There is one large branch called Yongning River within Naxi District and it affluxes to Yangtze River, which confronts the branches mutually, resulting in the frequent flood disasters. After the founding of People's Republic of China, the urban flood disaster becomes more serious with the development of national economy and municipal construction. Serious flood happened in 1954, 1955, 1966, 1981, 1991 and 1995 respectively, which indicated that the urban area is mainly affected by the flood of Yangtze River [2]. The loss becomes more severe if flood happens to Yangtze River and Yongning River at the same time. The most typical floods occurred in 1955 and 1991. Naxi still suffers the flood threat in recent years and flood happens frequently, causing huge economic loss and threatening people's economy and lives [3].

With the continuous development of national economy of this district and the acceleration of urban construction, the losses caused by flood disaster would be on the rise yearly and the improvement of flood prevention system and engineering construction will sooner or later affect the local economic development of Naxi District and the safety and investment environment of the mass. Flood disaster has become one of the main factors restraining the sustainable development of national economy of this region.

\section{ACtUAl SituATION OF FLOOD PREVENTION AND CONTROL AND EXISTING PROBLEMS}

\section{A. Actual Situation of Flood Prevention and Control}

Engineering measures: Naxi District strengthens implementing the flood bank project in recent years to improve the human settlement environment. The planned flood bank of Yangtze River and Yongning River within Naxi District is $4.9 \mathrm{~km}$ long and $18 \mathrm{~m}$ wide. The urban flood bank of Naxi will integrate the functions such as flood prevention, greening and recreation. Naxi District has implemented $700 \mathrm{~m}$ long upper dam flood bank, 500m long Yongning River flood dam and $300 \mathrm{~m}$ long flood bank at the east of the river as early as 2003 . The total construction length thus reaches $1.8 \mathrm{~km}$.

Non-engineering measures: the construction projects along the river shall be strictly controlled; flood prevention and waterlogging control office of this district is designated to be responsible for the daily work about it; the maintenance and management of the rivers and drainage facilities shall be strengthened.

\section{B. Existing Problems}

As the urban area is almost located in Grade 1 or Grade 2 
terrace or alluvial plain and the flood in the urban area is thus characterized by large peak height and significant variation of water level amplitude. The flood disaster there is thus very frequent and serious. At present, flood prevention of Naxi District contains the problems in the following several aspects [4].

1) Banks that have been established along the reach is small in quantity. $1.8 \mathrm{~km}$ bank has been established within the bank, accounting for $28 \%$ of the whole length of reach only. The protection scope is thus very small and unable to ensure the safety of Naxi District if flood occurs. No effective prevention system is actually formed.

2) The channel improvement and spoil and rubbish damped result in the higher riverbed of Yangtze River and Yongning River but the river width becomes smaller; due to the water and soil loss in the upstream of Yangtze River, the channel filling becomes more serious and flood carrying capacity is reduced.

3) Imperfect and sub-standard drainage system and insufficient cross section. A majority of urban drainage systems are water and sewage confluence systems, which are characterized by small and sub-standard cross section and serious blockage. Mountainous torrent easily happens in case of rainstorm [5].

III. HYDROLOGICAL ANALYSIS AND CALCULATION OF FLOOD PREVENTION AND WATERLOGGING CONTROL

\section{A. Hydrological Analysis and Calculation of Flood Prevention}

Located in the southern part of Sichuan Basin, Naxi District, Luzhou City, Sichuan Province lies to the south of Yangtze River and on both banks of downstream of Yongning River. It connects Hejiang County eastward, Xuyong County southward, Jiang'an County westward and is adjacent to Jiangyang District, Luzhou City northward. There are altogether over 130 rivers in different sizes within Naxi District, Luzhou City with the total length of $640 \mathrm{~km}$. Yongning River is the largest branch of Yangtze River within Naxi District, with the basin area of $3,228 \mathrm{~km}^{2}$ and riverway of $164 \mathrm{~km}$. It flows through the middle of the district and then affluxes to Yangtze River by running through Shangma, Huguo, Quba, Tianxian and Anfu, with the length within the district of $56.8 \mathrm{~km}$. Daoliu River is between east longitude of $105^{\circ} 22^{\prime} 03^{\prime \prime} \sim 105^{\circ} 33^{\prime} 25^{\prime \prime}$ and north latitude of $28^{\circ} 48^{\prime} 12^{\prime \prime} \sim 28^{\circ} 47^{\prime} 25^{\prime \prime}$. Originated from high mountains and lofty hills where Jiangyang District and Naxi District meet, it flows through Longche Town, Mianhuapo Town and Anfu Subdistrict Office of Naxi District and affluxes to Yangtze River in Toujiliang of Naxi District.

\section{1) Flood characteristics}

Yangtze River and Yongning River are the main rivers that affect the urban flood prevention safety of Naxi District. Besides, the big and small branches that flow through the downtown also exert certain influence on the urban flood prevention and waterlogging control safety [6].

The flood of Yangtze River results from rainstorm and the flood magnitude is directly related to the scope and intensity of upstream rainstorm, secondary storm rainfall, rainstorm center and movement direction [7]. According to the statistics of the actual data of Luzhou Gaging Station, the flood of Yangtze River almost happens in June $\sim$ September, particularly in July and August. The maximum range of stage of flood is $20.3 \mathrm{~m}$ (in 1948) and the flood peak exists for a long time, generally 10 20 days.

\section{2) Sediment characteristics}

Naxi urban area is in the main stream reach of the utmost upstream of Yangtze River after the confluence of heavily silt-carrying rivers such as Jinsha River, Min River meet. The sediment runoff and sedimentation concentration belong to the largest reach of the main stream of Yangtze River [8].

Originated from the mouth of Batang River, Yushu, Qinghai Province, Jinsha River reaches the mouth of Min River, Yibin, Sichuan Province by flowing through four provinces like Qinghai, Tibet, Sichuan, Yunnan, with the total length of $2,290 \mathrm{~km}$, accounting for $2 / 3$ of the main stream length in the upstream of Yangtze River. The catchment area from Batang River Mouth of Yushu to the mouth of Min River of Yibin is 362,000km2, accounting for $36 \%$ of the area of basin in the upstream of Yangtze River with the difference of level of over $3,300 \mathrm{~m}$ and the average sloping of $1.45 \%$.

The maximum sediment concentration measured in Pingshan Station, Jinsha River is $24.2 \mathrm{~kg} / \mathrm{m}^{3}$ but that for several years is $1.70 \mathrm{~kg} / \mathrm{m}^{3}$. The annual change of the sediment runoff is significant with the annual maximum one of 501 million $t$ (in 1974) and the annual minimum one of 126 million $t$ (in 1975); the difference of both is about 3.98 times. The average sediment runoff for years is 255 million $t$ but the distribution of it within the year is extremely uneven and mainly in June October, the period of which is the flood season, accounting for about $96 \%$ of the sediment runoff throughout the year; in particular, the sediment runoff in July $\sim$ September is about $76 \%$ of that of the whole year [9].

See Table I for the average suspended load level for years after the statistics and analysis of the grain size distribution data of Pingshan Station for years after 1987.

Min River is originated from the southern foot of Min Mountain and flows to Yangtze River in Yibin at the left bank through Songpan, Maowen, Wenchuan, Dujiang Weir, Chengdu Plain, Le Mountain, Nadadu River and Wutongqiao from north to south, with the total length of $735 \mathrm{~km}$, the basin area about $136,000 \mathrm{~km}^{2}$ and the natural difference of level of $3,650 \mathrm{~m}$. It is the branch with the largest water yield in Yangtze River basin.

The sediment concentration measured in Gaochang Station of Min River for years is $0.56 \mathrm{~kg} / \mathrm{m}^{3}$ and the annual change of the sediment runoff is significant, with the annual maximum one of 122 million $t$ (in 1966) and the annual minimum one of 15.2 million $t$ (in 2002). The difference of both is about 8 times. The average sediment runoff for years is 48.2 million $t$ but the distribution of it within the year is extremely uneven and mainly in May October, the period of which is the flood season, accounting for about $99 \%$ of the sediment runoff throughout the year; in particular, the sediment runoff in July $\sim$ September is about $84 \%$ of that of the whole year [10].

After the statistics and analysis of grain size distribution 
data of Gaochang Station for years after 1987, the change of the suspended sediment particle size component of this station is insignificant and the maximum particle size is smaller than $1.0 \mathrm{~mm}$. See Table II for the average suspended load grading for years.

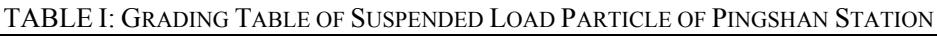

\begin{tabular}{|c|c|c|c|c|c|c|c|c|c|c|}
\hline Particle size $(\mathrm{mm})$ & 0.005 & 0.01 & 0.025 & 0.05 & 0.10 & 0.25 & 0.5 & 1.0 & 2.00 & Median size $(\mathrm{mm})$ \\
\hline Sediment weight percent smaller than one particle size (\%) & 21.3 & 31.1 & 47.1 & 63.8 & 79.1 & 90.4 & 97.8 & 99.9 & 100 & 0.028 \\
\hline
\end{tabular}

TABLE II: GRADING TABLE OF SUSPENDED LOAD PARTICLE OF GAOCHANG STATION

\begin{tabular}{|c|c|c|c|c|c|c|c|c|c|}
\hline Particle size $(\mathrm{mm})$ & 0.005 & 0.01 & 0.025 & 0.05 & 0.10 & 0.25 & 0.5 & 1.0 & Median size $(\mathrm{mm})$ \\
\hline Sediment weight percent smaller than one particle size (\%) & 11.4 & 20.4 & 37.7 & 57.0 & 82.8 & 94.1 & 99.7 & 100 & 0.043 \\
\hline
\end{tabular}

No sediment data of Naxi urban area is available and the average suspended load sediment runoff of engineering reach for years through the integration and statistics of the data from Pingshan and Gaochang Station is about 303.2 million $t$. According to statistics of actual water level data of Luzhou Gaging Station, the flood of Yangtze River in Naxi urban area almost happens in June September and the sediment runoff throughout the year is generally in June September, which is the flood season. The sediment runoff in June $\sim$ September accounts for $90 \%$ of that of the whole year. The sediment yield of the engineering reach in flood season is estimated to be $90 \%$ of that throughout the year, about 272.88 million $t$. The bed load sediment yield is estimated as $10 \%$ of the suspended load sediment yield, about 27.29 million $\mathrm{t}$.

\section{3) Design flood}

See Table III for the data of the main basis for the design flood of planning this time. Luzhou Gaging Station has been established along the main stream of Yangtze River below the confluence mouth of Tuo River, Lizhuang Gaging Station is along the main stream of the upstream of Yangtze River, Lijiawan Gaging Station is set along Tuo River and Xietanzi Hydrometric Station along Yongning River.

TABLE III: OBSERVATION SHEET OF HYDROMETRIC STATION DATA

\begin{tabular}{|c|c|c|c|c|c|}
\hline \multirow{2}{*}{ River } & \multirow{2}{*}{ Station } & \multirow{2}{*}{$\begin{array}{l}\text { Controlling } \\
\text { area }(\mathrm{km} 2)\end{array}$} & \multicolumn{3}{|c|}{$\begin{array}{l}\text { Main observation items and starting and } \\
\text { ending time }\end{array}$} \\
\hline & & & Water level & Flow & Sediment \\
\hline $\begin{array}{l}\text { Yongning } \\
\text { River }\end{array}$ & Xietanzi & 1168 & $1957 \sim 1995$ & 1957 1995 & \\
\hline $\begin{array}{l}\text { Tuo } \\
\text { River }\end{array}$ & Lijiawan & 23283 & $\begin{array}{c}\text { April, } \\
1941 \sim \text { now }\end{array}$ & $\begin{array}{l}\text { February, } \\
\text { 1951 now }\end{array}$ & 1957 now \\
\hline \multirow{2}{*}{$\begin{array}{l}\text { Yangtze } \\
\text { River }\end{array}$} & Lizhuang & 639227 & $\begin{array}{l}\text { September, } \\
1943 \sim \text { now }\end{array}$ & $1943.9 \sim 1959$ & \\
\hline & Luzhou & 673722 & $\begin{array}{l}\text { 1939 1948, } \\
1952 \sim \text { now }\end{array}$ & 1954 1959 & \\
\hline
\end{tabular}

4) Water surface profile of design flood of Naxi in Yangtze River reach

Calculation method of water surface profile: The water surface profile of design flood is calculated according to the constant non-uniform flow energy equation (i.e., Bernoulli equation). The calculation formula is as follows:

$$
Z_{d}+(\alpha+\xi) \frac{Q^{2}}{2 g A_{d}^{2}}+\frac{\Delta S Q^{2}}{2 K_{d}^{2}}=Z_{u}+(\alpha+\xi) \frac{Q^{2}}{2 g A_{u}^{2}}-\frac{\Delta S Q^{2}}{2 K_{u}^{2}}
$$

where: $Z_{u}, Z_{d}$-Water level of reach of upstream and downstream, m;

$A_{u}, A d$-Discharge area of reach of upstream and downstream, $\mathrm{m}^{2}$;
$K_{u}, K d$-Modulus of discharge of reach of upstream and downstream, $\mathrm{m}^{3} / \mathrm{s}$;

$\xi$-Coefficient of local head loss;

$\Delta S$ - Spacing of reach of upstream and downstream, m;

$Q-$ Cross section flow, $\mathrm{m}^{3} / \mathrm{s}$;

$g$-Acceleration of gravity, subject to $9.81 \mathrm{~m} / \mathrm{s}^{2}$.

Direct iteration algorithm is used for resolution and calculating the water surface profile of shifting bed.

Calculation for boundary condition:

- 1/5,000 topographic map;

- "91.8" surveyed flood water surface profile of Yangtze River reach;

- Stage-discharge relation of Luzhou Gaging Station

Riverway interval roughness factor:

According to "91.8" historical flood water surface profile of Yangtze River reach investigated, the formula below is used

$$
n=\frac{\overline{\mathrm{AR}}^{2 / 3}}{\mathrm{Q}}\left(\frac{\mathrm{Zu}-\mathrm{Zd}}{\Delta \mathrm{S}}-(\alpha+\xi) \frac{\mathrm{Q}^{2}}{2 \mathrm{~g} \Delta \mathrm{S}}\left(\frac{1}{\mathrm{~A}_{\mathrm{d}}^{2}}-\frac{1}{\mathrm{~A}_{\mathrm{u}}^{2}}\right)^{1 / 2}\right.
$$

The reverse interval roughness factor of Yangtze River reach is $n=0.028 \sim 0.04$ through calculation.

- Water surface profile of design flood;

Water surface profile of Naxi along Yangtze River reach:

TABlE IV: CAlCUlated Result of WATER SuRfaCe PROFILE of NAXI DISTRICT ALONG YANGTZE RIVER REACH (UNIT: M)

\begin{tabular}{lcccc}
\hline \hline No. & Place & Mileage & $\mathrm{P}=2 \%$ & $\mathrm{P}=5 \%$ \\
\hline C1 & & $0+000$ & 249.02 & 247.92 \\
C2 & & $0+865$ & 249.18 & 248.03 \\
C3 & Maliutuo & $1+688$ & 249.32 & 248.19 \\
C4 & The mouth of & $2+718$ & 249.90 & 248.36 \\
C5 & Yongning River & $3+615$ & 250.16 & 248.53 \\
C6 & & $4+460$ & 250.42 & 248.77 \\
C7 & & $5+260$ & 250.68 & 248.96 \\
\hline \hline
\end{tabular}

\section{B. Hydrological Analysis and Calculation of Waterlogging Control}

\section{1) Design rainstorm}

The flood prevention planning area of Naxi District, Luzhou belongs to the subtropical monsoon area which is affected by the alternating activities of both northern continental dry and cold monsoon and southern warm and wet monsoon; as a result, heavy rain or rainstorm happens 
frequently [11]. Although the rainstorm in Naxi District cannot cause the abrupt rise of the water level of Yangtze River but it definitely brings partial flood, landslide, rock fall, debris flow, collapse, house collapse, farmland destruction, all of which will result in the considerable economic loss.

The rainstorm data is mainly based on the actual data of Naxi Meteorological Station and the maximum storm rainfall for 1/6, 1, 6 and 24 hours of Naxi Meteorological Station in 1980 2008 is collected in design this time. Pearson Type III line is used after frequency analysis and calculation.

Pearson Type III line is adopted according to the data of rainstorm in 1/6, 1, 6 and 24 hours in 1980 2008 of Naxi Meteorological Station [12].

\section{2) Causes and characteristics of waterlogging}

The waterlogging of Naxi District is related to the characteristics of the rainstorm flood in the district, actual situation of flood bank and drainage system design. No effective prevention system has been formed in Yangtze River reach of Naxi District. In case that flood (water level of Luzhou Gaging Station reaches $236.52 \mathrm{~m}$, which is equivalent to 20-year flood) happened to Yangtze River, a majority of drainage outlets in the downtown will be submerged. If the water level of river keeps increasing and rainstorm happens to the city as well, the unsmooth municipal drainage will cause local flood disaster [13].

To resolve the flood and waterlogging of Naxi District, the first thing that we need to do is to improve the flood prevention standard of drainage channels and the drainage pipeline network; the second is to establish and improve drainage facilities so as to drain and adjust the blockages smoothly and minimize the waterlogging disasters; the third is to remove the discharge barrier of the riverway to ensure the smooth river water and reduce the water level of Yangtze River.

TABLE V: OUTCOME TABLE OF DESIGN RAINSTORM OF NAXI METEOROLOGICAL STATION

\begin{tabular}{|c|c|c|c|c|c|c|c|}
\hline \multirow{2}{*}{ Period } & \multirow{2}{*}{$\begin{array}{l}\text { Mean } \\
\text { value } \\
(\mathrm{mm}) \\
\end{array}$} & \multirow{2}{*}{$\mathrm{Cv}$} & \multirow{2}{*}{$\mathrm{Cs} / \mathrm{Cv}$} & \multicolumn{4}{|c|}{ Remarks } \\
\hline & & & & $1 \%$ & $2 \%$ & $5 \%$ & $10 \%$ \\
\hline $1 / 6$ hours & 18.7 & 0.32 & 3.5 & 37.2 & 34.2 & 30.1 & 26.7 \\
\hline 1 hour & 48.2 & 0.52 & 3.5 & 136 & 120 & 97.8 & 81.2 \\
\hline 6 hours & 77.2 & 0.55 & 3.5 & 229 & 200 & 162 & 133 \\
\hline 24hours & 104 & 0.55 & 3.5 & 308 & 269 & 218 & 179 \\
\hline
\end{tabular}

\section{CONCLUSIONS}

In the light of characteristics of riverway, the topographic and geological conditions alongside, as well as the target of flood control planning, the arrangements of the bank protection project in Naxi District shall observe the following principles:

1) Making the best use of the natural pattern of river regime, the bank protection project arrangement shall be consistent with the flow direction and parallel to the mainstream of great flood.

2) Making overall, unified planning of projects that have been built or planned on both banks, upstream or downstream.

3) Impact on flood control shall be put in the first place to ensure enough flood section. Meanwhile, impact on other aspects like navigation shall be noted.

4) To make the embankment line as smooth as possible, neighboring sections shall be linked in a gentle manner to avoid fold line or sharp turn.

5) Favorable terrains shall be utilized fully, and enough areas of flood plains are supposed to be reserved.

6) Combining the topographic and geological conditions of the riverway and giving thorough consideration to the comprehensive benefits of all the works, including the flood control, transportation, bank protection, urban construction and greening along rivers, etc. thus to increase the feasibility and economical efficiency of the project.

In the flood control and management project, the bank protection shall be set as a priority. To enhance the flood control capacity in a comprehensive way, efforts must be made in such events as the protection and treatment of the banks in urban areas, comprehensive treatment of riverway, water and soil conservation. By implementing the engineering and non-engineering flood control measures and upgrading the standard for flood control of the Naxi District, Luzhou City, the capacity and security of flood control will be improved to meet the needs for urban construction and development.

\section{ACKNOWLEDGMENT}

The authors would like to express appreciations to colleagues in our laboratory for their valuable comments and other helps.

\section{REFERENCES}

[1] W. Zhang, "Slope Protection of Highway Safety and Ecological Landscaping," Traffic Science and Technology, vol. 5, pp. 29-31, May 2005 .

[2] J. Wang and Z. L. Liu, "Spray the anchor net technology in high and steep slope protection application," Shanxi Traffic Science and Technology, vol. 10, pp. 58-59, October 2005.

[3] Z. H. Wang and X. G. Chen, "Highway rock slope of common structure type and protective measures," Technology of Highway and Transport Technology Edition: Technology Forum, vol. 3, pp. 66-68, March 2006.

[4] J. Y. Zhang, D. P. Zhou, and S. C. Li, "Study on green method for rock slope," Chinese Journal of Rock Mechanics and Engineering, vol. 9 , pp. 1400-1403, September 2006.

[5] C. X. Zhong and W. Zhang, "Traditional revetment and ecological revetment," Red Water River, vol. 4, pp. 136-139, April 2006.

[6] F. Jiang, "Analysis of vegetation slope protection technology application in china," Civil Engineering Abstracts, Chengdu: Southwest Jiao Tong University press, 2006.

[7] J. J. Ye and W. N. Xu, "Review and prospect of slope vegetative treatment, Research of Soil and Water Conservation, vol. 1, pp. 173177, January 2005.

[8] T. Q. Wang, W. J. Xu, and J. J. Ye, "The excavated rock slope green technology and methods," Journal of China Three Gorges University: Natural Science Edition, vol. 2, pp. 101-104, February 2003.

[9] W. N. Xu and J. J. Ye, "Vegetation Concrete Slope Green Technology," Problems of Water Resources and Hydropower Technology, vol. 35, pp. 50-52, November 2006.

[10] Y. B. Du, B. Guo, and X. B. You, "Thick layer base material spraying adaptive application," Traffic Science and Technology, vol. 3, pp. 7072, March 2006.

[11] Y. G. Chen, "Climbing plants in highway rock slope application technology research," Hunan Transportation Research, pp. 34-36, 2005.

[12] G. G. Xu and Q. W. Lai, The Southwest Road Slope Ecological Management Practice, vol. 19, pp. 66-69, September 2007.

[13] H. Fang and J. P. Lin, "Current situation and prospect of vegetation slope protection," Research of Soil and Water Conservation, vol. 3, pp. 283-285, March 2004. 


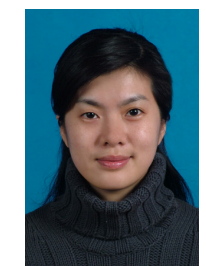

Juan Dai is the member of IACSIT, who was born in Wuhan in the year of 1980, studied in China University of Geosciences (Wuhan) during Sep. 2007 to Jun. 2010 and acquired Doctor Degree in GIS, research direction center on urban flood control and river ecology.

She participated in research works of Natural Science Foundation of China, 948 Project, and the Three Gorges Fund. Participated in declaration works for editing and revision of hydrotechnics guidelines and implementing the strictest water resources management system. Specific projects contain Urban Rainfall Flood Stimulation, Key Technology Research on Reservoir Bank Treatment and Construction of Ecological Barrier of Three Gorges,
Research on Ecological System Protection and Restoration of Medium and Small Rivers of Three Gorges Reservoir Region and Research on Key Technology for Environmental Treatment of Urban River System and Demonstration Project.

Dr Dai is the member of Geography Society, participated in China's Environmental Flow Symposium, Exchange Symposium for Water Environment Pollution Control and Ecological Restoration and Innovation, Exchange Symposium for River Regulation and Ecological Restoration Technology. And acquired the third Prize of Excellent Paper for National River Regulation and Ecological Restoration Technology Summary. 